\title{
A Retroperitoneal Inflammatory Myofibroblastic Tumor Mimicking a Germ Cell Tumor of the Undescended Testis: A Case Report and Literature Review
}

\author{
Seul-Bi Lee1, Jung-Hee Yoon ${ }^{1 *}$, Seung-Ho Kim¹, Yedaun Lee1, Jin-Soo Lee1, Jung-Wook Seo² \\ ${ }^{1}$ Department of Radiology, Inje University Haeundae Paik Hospital, College of Medicine, Busan, South Korea \\ ${ }^{2}$ Department of Radiology, Inje University Ilsan Paik Hospital, College of Medicine, Goyang-si, South Korea \\ Email: *radyjh@hanmail.net
}

How to cite this paper: Lee, S.-B., Yoon, J.-H., Kim, S.-H., Lee, Y., Lee, J.-S. and Seo, J.-W. (2016) A Retroperitoneal Inflammatory Myofibroblastic Tumor Mimicking a Germ Cell Tumor of the Undescended Testis: A Case Report and Literature Review. Advances in Computed Tomography, $5,35-41$

http://dx.doi.org/10.4236/act.2016.53004

Received: October 2, 2016

Accepted: November 14, 2016

Published: November 17, 2016

Copyright $\odot 2016$ by authors and Scientific Research Publishing Inc. This work is licensed under the Creative Commons Attribution International License (CC BY 4.0).

http://creativecommons.org/licenses/by/4.0/

\begin{abstract}
We report here a case of an inflammatory myofibroblastic tumor in the retroperitoneum, which mimicked a germ cell tumor of the undescended testis. A 75-year-old healthy man presented with a palpable abdominal mass. On the computed tomography image, there was large, well-defined soft tissue mass in the left side of the retroperitoneum, and there was no visible left testis or seminal vesicle. After contrast enhancement, the mass appeared to be relatively homogeneous, considering its large size. With ultrasonography, it appeared as a well-defined, hypoechoic mass with intratumoral vascularity. This solid mass was surgically diagnosed as an inflammatory myofibroblastic tumor.
\end{abstract}

\section{Keywords}

Inflammatory Myofibroblastic Tumor, Computed Tomography,

Ultrasonography, Retroperitoneal

\section{Introduction}

An Inflammatory Myofibroblastic Tumor (IMT), also well known as an inflammatory pseudotumor, is a rare benign lesion of unknown etiology. It usually affects children and young adults and commonly involves the lung and orbit. Approximately 17 cases of retroperitoneal IMT were reported in the English literature. Furthermore, case reports containing imaging of retroperitoneal IMT were even rarer, to our knowledge. Here, we describe the radiologic findings from Computed Tomography (CT) and ultrasonogra- 
phy (US) of a case of retroperitoneal IMT, which mimicked a germ cell tumor arising from the undescended testis in a 75-year-old man.

\section{Case Report}

A 75-year-old previously healthy man presented with a palpable abdominal mass and weight loss. The patient did not have any special medical history. His physical examination was normal except for the palpable abdominal mass. Laboratory tests revealed mild anemia (Hgb $9.9 \mathrm{~g} / \mathrm{dl}$, normal range 14 - 18) and markedly increased C-Reactive protein $(13.19$, normal range 0 - 0.05). On a contrast-enhanced abdominopelvic CT, a $6.3 \times$ $9.5 \times 9.5 \mathrm{~cm}$, well-defined isodense mass with a small internal cystic or necrotic portion was detected in the left retroperitoneum, abutting the left psoas muscle. The mass showed gradual enhancement and contained relatively homogeneous mass parenchyma despite its large size (Figure 1). The kidney could be visualized in the left renal fossa, but the left testis and seminal vesicle were not visible in the left scrotal sac (Figure 1(c) and Figure 1(e)). This finding indicated either incomplete descent or agenesis of the left testis. In the clinic, a malignant germ cell tumor, especially a germ cell tumor arising from the undescended left testis, was included in the first differential diagnosis, but laboratory results of b-human chorionic gonadotropin, alpha-fetoprotein, prostatespecific antigen were all within normal limit. Then, the patient underwent an USguided needle biopsy. The sonographic findings included a slightly hypoechoic solid mass with an internal small cystic portion at the time of biopsy (Figure 2(a)). Color Doppler imaging revealed intratumoral hypervascularity (Figure 2(b)). The biopsy specimen contained an aggregation of mixed inflammatory cells, including neutrophils, plasma cells and foamy histiocytes. The results of the CK (cytokeratins) and C-kit immunohistochemistry were negative. The results of biopsy were unsatisfactory with the risk of malignancy, especially considering the patient's age. Therefore, we followed up after 1 month with US. The follow-up US showed that the retroperitoneal mass increased in size from $8 \times 7 \mathrm{~cm}$ to $9 \times 8.7 \mathrm{~cm}$. Eventually, the patient underwent transperitoneal laparoscopic excision of the left retroperitoneal tumor. Gross examination showed a well-circumscribed, multinodular solid mass of yellow gray color with some cystic change. Microscopic examination showed proliferation of myofibroblasts with mixed inflammatory cell infiltration (Figure 3). Mitotic activity was low, and cellular atypism was minimal. Immunohistochemical staining was negative for S100, epithelial membrane antigen, CK, desmin and ALK (anaplastic lymphoma kinase) but positive for smooth muscle actin and cluster of differentiation 34 . These findings were consistent with IMT.

\section{Discussion}

IMT has been reported in various sites in the abdomen, including the liver, spleen, pancreas, adrenal gland, kidney, retroperitoneum, mesentery, gastrointestinal and urinary tract [1] [2] [3] [4] [5]. It most commonly affects children and young adults and frequently occurs in the lungs [2]. Extrapulmonary IMT accounts for approximately 5\% 


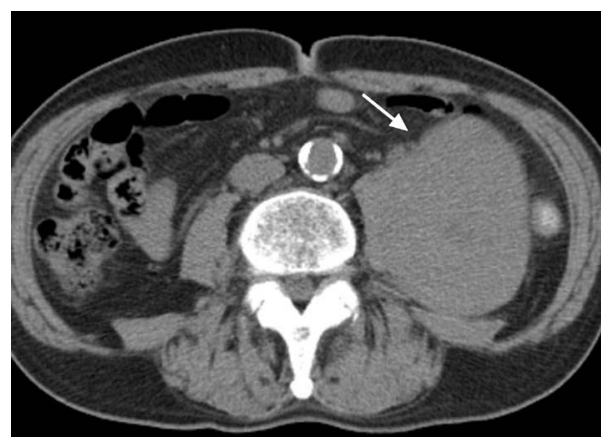

(a)

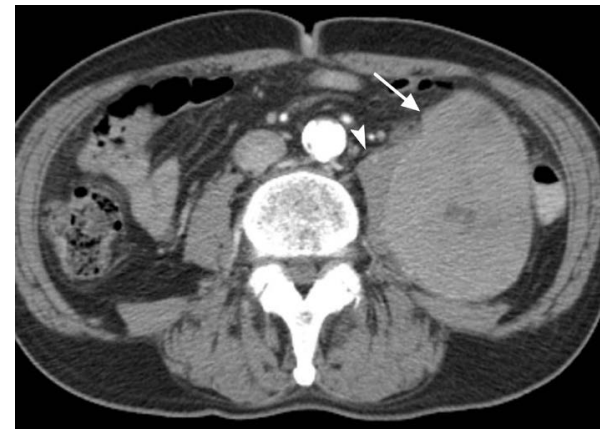

(b)

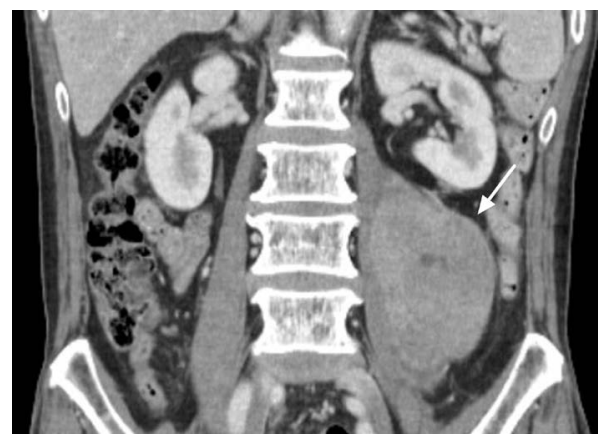

(d)

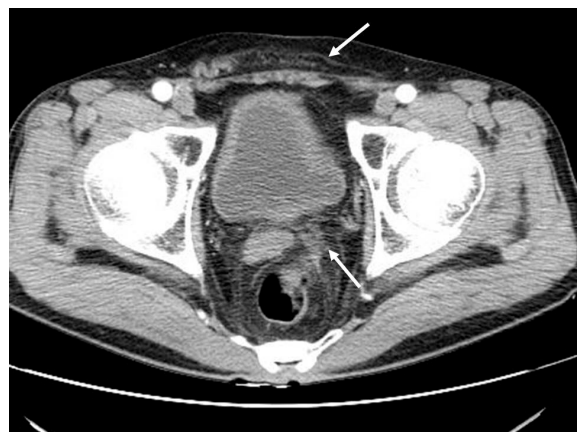

(c)

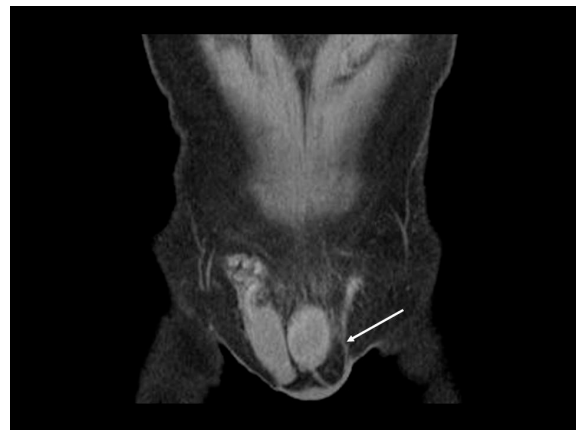

(e)

Figure 1. A 75-year-old man with an incidental finding of a left retroperitoneal inflammatory myofibroblastic tumor ((a)-(e)). Axial CT images at the unenhanced (a), the arterial phase ((b), (c)) and a coronal reconstructive image at the portal phase ((d), (e)) show a well-defined and well-enhanced mass with an internal cystic or necrotic portion (arrow) in the left retroperitoneum, abutting the left psoas muscle (arrowhead at (b)). It shows consistent enhancement at the delayed phase (not shown). There is no visible spermatic cord or seminal vesicle (arrow at (c)), or left testis (e).

of IMT [6]. Retroperitoneal involvement is rare in extrapulmonary IMT. Coffen et al. conducted a clinicopathologic study of 84 cases of extrapulmonary IMT, including 4 cases of retroperitoneal IMT [7]. The patients often presented with features of inflammation, such as fever and weight loss. Laboratory abnormalities also included the stigma of inflammation, such as the hypochromic microcytic anemia in our patient.

The differential diagnosis for a retroperitoneal solid mass includes both neoplastic and nonneoplastic entities. Nonneoplastic entities include retroperitoneal fibrosis and 


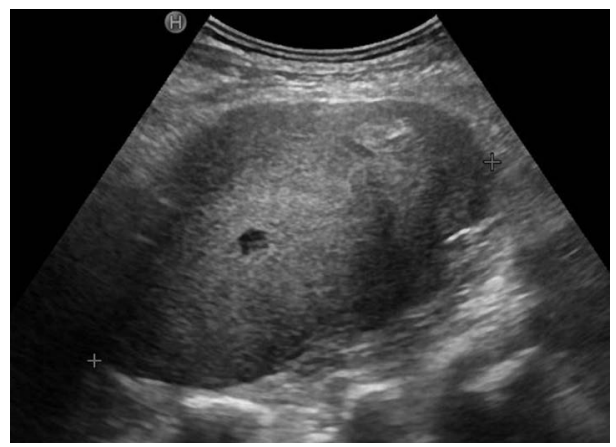

(a)

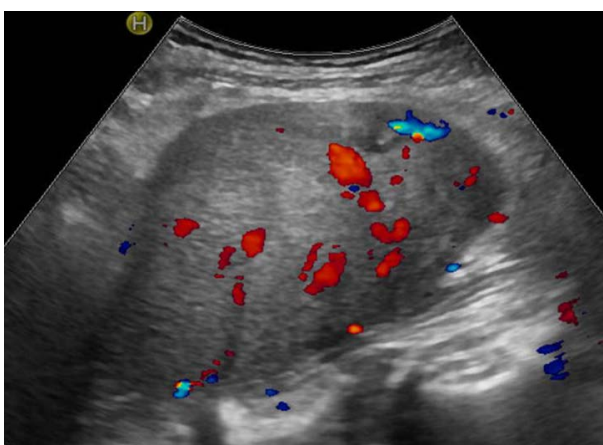

(b)

Figure 2. Grey scale US (a) shows an oval shaped, slightly hypoechoic solid mass with an internal small cystic portion in the left retroperitoneum. Color Doppler US (b) reveals intratumoralhypervascularity.

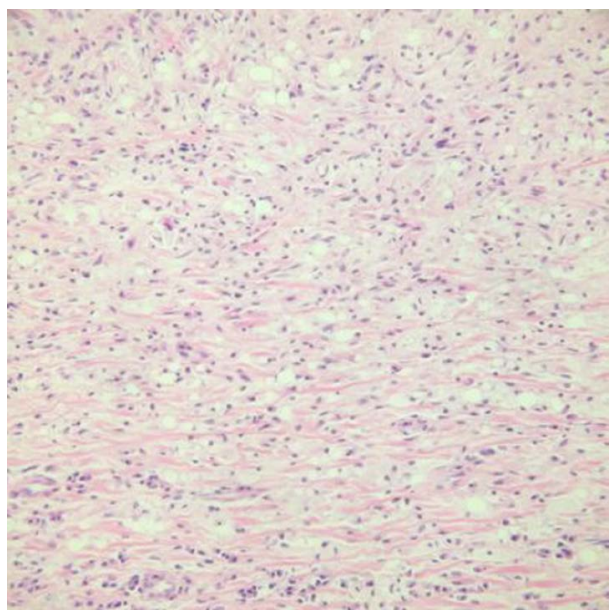

(a)

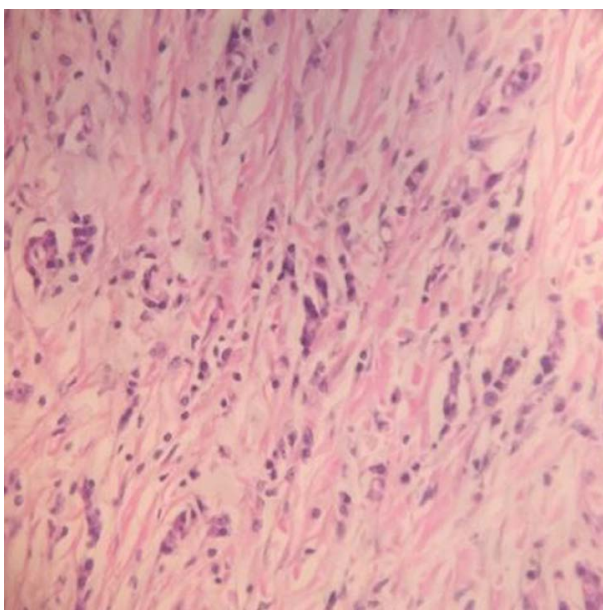

(b)

Figure 3. Photomicrograph of a histological specimen shows proliferation of myofibroblasts with mixed inflammatory cell infiltration (including neutrophils, plasma cells and foamy histiocytes), low mitotic activity and minimal cellular atypism (hematoxylin-eosin stain, original magnification $\times 400$ (a) and $\times 1000(\mathrm{~b}))$.

extramedullary hematopoiesis, which, on occasion, can produce bulky masses. The large size, well-defined contour and relatively homogenous enhancement of the mass in our case made these diagnoses unlikely. Neoplastic entities can have mesodermal origins, neurogenic origins, lymphoid or hematologic origins, and germ cell, sex cord, and stromal cell origins. Of these neoplastic entities, primary retroperitoneal tumors including malignant fibrous histiocytoma, leiomyosarcoma show usually large infiltrating, heterogeneously enhancing soft tissue mass containing extensive necrosis or hemorrhage. Neurogenic tumors show large heterogeneous appearance usually located at paravertebral region. Differential diagnosis may be helpful for addressing the overlap in the imaging findings of many of these masses. Lymphoma and metastatic lymphadenopathy are two of the most common soft-tissue masses observed in the retroperitoneum and should always be considered. However, in this case, there was no visible tes- 
tis or seminal vesicle in the left scrotal sac, which suggested the possibility of an undescended testis. So, our first impression was that the mass was a germ cell tumor arising from the undescended testis. It could also be classified as a huge retroperitoneal mass with nonspecific radiologic findings.

IMT is a rare benign condition which mimics malignancy both clinically and radiologically. The definitive diagnosis is based on histological evaluation of tissue specimens characterized by proliferative myofibroblasts or fibroblasts with inflammatory cell infiltration, such as histiocytes, plasma cells and lymphocytes [1]. This tumor was previously described as an inflammatory pseudotumor, inflammatory myofibroblastoma, lymphoplasmacytic histiocytoma, and fibrous pseudotumor until 1994, when IMT was established as a distinct low-grade malignancy by the World Health Organization [2]. Usually, IMT has a benign course, and in most cases, it is a slow growing, locally confined tumor with less metastatic potential [3]. The histogenesis of IMT is uncertain, but it is generally thought to arise as the result of an inflammatory reaction to surgery, trauma, malignancy, infection by the Epstein-Barr virus or the Human Herpes virus [4]. Others have insisted that a chromosomal rearrangement involving the ALK gene results in the activation of a tyrosine kinase receptor that could lead to abnormal expression [5].

The nonspecific radiologic findings of IMT in other locations have been reported in the literature. Contrast enhanced CT may show variable density with homogenous or heterogeneous masses. Larger lesions may have central necrosis. There are varying degrees and patterns of contrast enhancement [8] [9]. US also obtains variable patterns of echogenicity with ill-defined or well-circumscribed margins, while Doppler may reveal prominent vascular flow [9]. On magnetic resonance images, the appearance of these tumors is also variable. They are usually hypointense relative to skeletal muscle on T1weighted images, hyperintense on T2-weighted images and heterogeneously enhanced after administration of contrast material [10]. These variable radiologic findings may be attributed to histologic complexity with the duration of the disease process, the amount of fibrous tissue and the degree of cellular infiltration. Generally, IMT has an innocuous clinical course, despite its variable biological potential. Complete surgical resection is the treatment of choice for most IMTs, with the exception of orbital lesions. Treatment of orbital IMT usually begins with high doses of systemic steroids. Approximately $50 \%$ of orbital IMT cases resolve completely with steroid treatment. Antibiotics have also been used in some cases. Additionally, several cases of spontaneous regression have been reported. Radiation therapy has been attempted in unresectable cases and when cases have poor responses to steroid therapy. In summary, we reported a case of IMT, an extremely rare quasi-neoplastic retroperitoneal mass, which was first suspected to be a germ cell tumor arising from the undescended testis. Differentiation from malignant retroperitoneal neoplasm was not possible preoperatively. Fine-needle biopsy may fail to yield a sufficient volume of tumor tissue to make a definite diagnosis. Retroperitoneal IMTs are rare presentations of a rare disease. Although they are unlikely to occur in the retroperitoneum, IMTs should be kept in mind as a possibility. 


\section{References}

[1] Horiuchi, R., Uchida, T., Kojima, T. and Shikata, T. (1990) Inflammatory Pseudotumor of the Liver: Clinicopathologic Study and Review of the Literature. Cancer, 65, 1583-1590. http://dx.doi.org/10.1002/1097-0142(19900401)65:7<1583::AID-CNCR2820650722>3.0.CO; $\underline{2-\mathrm{L}}$

[2] Bahadori, M. and Liebow, A.A. (1973) Plasma Cell Granulomas of the Lung. Cancer, 31, 191-208.

http://dx.doi.org/10.1002/1097-0142(197301)31:1<191::AID-CNCR2820310127>3.0.CO;2D

[3] Attili, S.V., Chandra, C.R., Hemant, D.K., Bapsy, P.P., RamaRao, C. and Anupama, G. (2005) Retroperitoneal Inflammatory Myofibroblastic Tumor. World Journal of Surgical Oncology, 3, 66. http://dx.doi.org/10.1186/1477-7819-3-66

[4] Xiang, J., Liu, X., Wu, S., Lv, Y. and Wang, H. (2012) Multiple Inflammatory Myofibroblastic Tumor of the Duodenum: Case Report and Literature Review. Journal of Gastrointestinal Surgery, 16, 1442-1445. http://dx.doi.org/10.1007/s11605-012-1883-9

[5] Choi, A.H., Bohn, O.L., Beddow, T.D. and McHenry, C.R. (2011) Inflammatory Myofibroblastic Tumor of the Small Bowel Mesentery: An Unusual Cause of Abdominal Pain and Uveitis. Journal of Gastrointestinal Surgery, 15, 584-588.

http://dx.doi.org/10.1007/s11605-010-1408-3

[6] Soga, H., Yao, A., Matsushita, K., Shimogaki, H. and Kawabata, G. (2011) Inflammatory Pseudotumor of the Retroperitoneum Removed via a Retroperitoneoscopic Approach. Journal of the Society of Laparoendoscopic Surgeons, 15, 272-274. http://dx.doi.org/10.4293/108680811X13071180406871

[7] Coffin, C.M., Watterson, J., Priest, J.R. and Dehner, L.P. (1995) Extrapulmonary Inflammatory Myofibroblastic Tumor (Inflammatory Pseudotumor). A Clinicopathologic and Immunohistochemical Study of 84 Cases. The American Journal of Surgical Pathology, 19, 859-872. http://dx.doi.org/10.1097/00000478-199508000-00001

[8] Abehsera, M., Vilgrain, V., Belghiti, J., Flejou, J.F. and Nahum, H. (1995) Inflammatory Pseudotumor of the Liver: Radiologic-Pathologic Correlation. Journal of Computer Assisted Tomography, 19, 80-83. http://dx.doi.org/10.1097/00004728-199501000-00015

[9] Nam, K.J., Kang, H.K. and Lim, J.H. (1996) Inflammatory Pseudotumor of the Liver: CT and Sonographic Findings. American Journal of Roentgenology, 167, 485-487. http://dx.doi.org/10.2214/ajr.167.2.8686633

[10] Torzilli, G., Inoue, K., Midorikawa, Y., Hui, A., Takayama, T. and Makuuchi, M. (2001) Inflammatory Pseudotumors of the Liver: Prevalence and Clinical Impact in Surgical Patients. Hepatogastroenterology, 48, 1118-1123. 


\section{Abbreviations}

IMT: inflammatory myofibroblastic tumor.

CT: computed tomography.

US: ultrasonography.

CK: cytokeratins.

ALK: anaplastic lymphoma kinase.

Submit or recommend next manuscript to SCIRP and we will provide best service for you:

Accepting pre-submission inquiries through Email, Facebook, LinkedIn, Twitter, etc.

A wide selection of journals (inclusive of 9 subjects, more than 200 journals)

Providing 24-hour high-quality service

User-friendly online submission system

Fair and swift peer-review system

Efficient typesetting and proofreading procedure

Display of the result of downloads and visits, as well as the number of cited articles

Maximum dissemination of your research work

Submit your manuscript at: http://papersubmission.scirp.org/

Or contact act@scirp.org 